\title{
The Pace of Vocabulary Growth Helps Predict Later Vocabulary Skill
}

\section{Citation}

Rowe, Meredith L., Stephen W. Raudenbush, and Susan Goldin-Meadow. 2012. "The Pace of Vocabulary Growth Helps Predict Later Vocabulary Skill." Child Development 83(2): 508-525.

\section{Published Version}

doi:10.1111/j.1467-8624.2011.01710.x

\section{Permanent link}

http://nrs.harvard.edu/urn-3:HUL.InstRepos:13041218

\section{Terms of Use}

This article was downloaded from Harvard University's DASH repository, and is made available under the terms and conditions applicable to Other Posted Material, as set forth at http:// nrs.harvard.edu/urn-3:HUL.InstRepos:dash.current.terms-of-use\#LAA

\section{Share Your Story}

The Harvard community has made this article openly available.

Please share how this access benefits you. Submit a story.

Accessibility 


\title{
The Pace of Vocabulary Growth Helps Predict Later Vocabulary Skill
}

\author{
Meredith L. Rowe \\ University of Chicago and University of Maryland
}

\author{
Stephen W. Raudenbush and \\ Susan Goldin-Meadow \\ University of Chicago
}

\begin{abstract}
Children vary widely in the rate at which they acquire words-some start slow and speed up, others start fast and continue at a steady pace. Do early developmental variations of this sort help predict vocabulary skill just prior to kindergarten entry? This longitudinal study starts by examining important predictors (socioeconomic status [SES], parent input, child gesture) of vocabulary growth between 14 and 46 months $(n=62)$ and then uses growth estimates to predict children's vocabulary at 54 months. Velocity and acceleration in vocabulary development at 30 months predicted later vocabulary, particularly for children from low-SES backgrounds. Understanding the pace of early vocabulary growth thus improves our ability to predict school readiness and may help identify children at risk for starting behind.
\end{abstract}

Children vary widely in the rate at which their vocabulary grows during early childhood (Fenson et al., 1994). It is plausible that children's early environments and social interactions influence the course of language acquisition (Snow, 1994, 1972). This theoretical perspective has led to many studies exploring the relation between parent and family factors (including parental talk to children and family socioeconomic status [SES]) and child vocabulary growth, and positive relations have been found between the two (see Hoff, 2006a, 2006b for a review). Thus, previous research strongly suggests that variations in early social-interactive environments are associated with variations in vocabulary growth rates, and highlights the importance of understanding the role that parent and family factors play in child language development.

The research was supported by grants from the National Institute of Child Health and Human Development: P01HD40605 to Susan Goldin-Meadow and K99/R00HD055522 to Meredith L. Rowe. We thank the other faculty members on the Program Project, Larry Hedges, Janellen Huttenlocher, Susan Levine, and Steve Small for their intellectual contributions to the project; Kristi Schonwald and Jason Voigt for administrative and technical support; and Karyn Brasky, Laura Chang, Elaine Croft, Kristin Duboc, Jennifer Griffin, Sarah Gripshover, Kelsey Harden, Lauren King, Max Masich, Carrie Meanwell, Erica Mellum, Molly Nikolas, Jana Oberholtzer, Lilia Rissman, Becky Seibel, Meredith Simone, Calla Trofatter, Kevin Uttich, Julie Wallman, and Kristin Walters for helping in data collection and transcription. We are grateful to the participating children and families.

Correspondence concerning this article should be addressed to Meredith L. Rowe, Department of Human Development, University of Maryland, College Park, 3304T Benjamin Building, College Park, MD 20742. Electronic mail may be sent to mrowe@ umd.edu.
It is important to understand not only the causes of variation in vocabulary growth rates, but also the consequences of acquiring vocabulary at different rates. Children's oral language skills when they enter kindergarten predict their later literacy skills and school success (Dickinson \& Tabors, 2001; Duncan et al., 2007; Snow, Burns, \& Griffin, 1998)—those who start behind tend to stay behind (Stanovich, 1986). The question we ask is whether differences in the rate at which vocabulary is acquired in the earliest stages predict children's vocabulary skills at school entry.

The obvious way to approach this question is to look to the period prior to school entry. We could, for example, focus on background factors and child data gathered at one moment in time during the preschool period and use this information to predict academic skills in the early elementary years. But information gathered at a single point in time can be misleading. Take, for example, two children who have the same vocabulary size at 30 months. Using observed vocabulary at 30 months to predict later language skill would lead us to predict identical vocabularies for the two children at school entry. However, if we knew that one of the two children was increasing her vocabulary at a faster rate than the other (i.e., had a greater slope at 30 months), we might predict that the first child would have a larger vocabulary at school entry

(C) 2012 The Authors

Child Development (C) 2012 Society for Research in Child Development, Inc. All rights reserved. 0009-3920/2012/8302-0012

DOI: $10.1111 /$ j.1467-8624.2011.01710.x 
than the second. In this case, looking at rate of change and/or rate of acceleration in vocabulary growth would be useful in predicting vocabulary size at school entry.

The goals of our study are threefold. First, we aim to understand the role that parent, family, and child factors play in explaining variation in child vocabulary acquisition across the early childhood period. Second, we aim to make use of our detailed longitudinal data to examine whether these early vocabulary growth trajectories can help us predict the language skills children bring with them to school. Third, we address the more practical issue of how useful early language data can be in predicting later vocabulary skill. Thus, this study extends the current body of research by investigating the role of early vocabulary growth in predicting later vocabulary skill.

Why study growth trajectories? Developmental phenomena, by definition, involve change. Questions about how and why abilities develop are therefore often of central interest. Not surprisingly, attempts to understand change over time in vocabulary growth have been part of the language acquisition literature for decades. The previous work in this area has taken two primary approaches. First, a large body of work has asked whether and when children experience a vocabulary spurt early in development. Researchers have hypothesized that around the age of 18 months (or around a vocabulary size of 50 words) children experience a marked increase in rate of vocabulary learning (Bloom, 1973; Nelson, 1973). Potential underlying mechanisms behind this phenomenon have been extensively investigated (e.g., Gopnick \& Meltzoff, 1987; Reznick \& Goldfield, 1992), as have individual differences in the vocabulary spurt (Goldfield \& Reznick, 1990). More recently, however, longitudinal methods for developmental research have progressed, and research highlighting the importance of sampling procedures (Adolph, Robinson, Young, \& Gill-Alvarez, 2008) and measurement in studying change over time has led to sophisticated work that challenges the existence of a vocabulary growth spurt (Ganger \& Brent, 2004; McMurray, 2007).

A second approach has been to more broadly model growth in vocabulary skill using frequent, intensive observations of parent-child interactions. This work has advanced our understanding of the course of vocabulary acquisition over discrete periods of development and has uncovered important factors related to vocabulary growth. For example, Huttenlocher and colleagues (Huttenlocher, Haight,
Bryk, Seltzer, \& Lyons, 1991) emphasized the important positive relation between parental talk to children and child vocabulary growth, a finding replicated for children who have experienced unilateral pre- or perinatal brain injury (Rowe, Levine, Fisher, \& Goldin-Meadow, 2009). Hart and Risley (1992) and Hoff (2003a, 2003b) showed that children of high SES displayed more rapid vocabulary growth than children from lower SES families. Recent work within a low-income sample found relations between other parental factors (such as language and literacy skills and maternal depression) and child vocabulary growth (Pan, Rowe, Singer, \& Snow, 2005). Many of these studies make use of individual growth modeling (Rogosa, Brandt, \& Zimowski, 1982), often through hierarchical linear modeling (Raudenbush \& Bryk, 2002), a powerful statistical method for addressing questions about change over time using a continuous outcome. This approach allows researchers to model individual, within-person change over time in vocabulary development, and to study predictors of between-person differences in change over time. Growth modeling is appropriate for constructs such as vocabulary, where the unit of measurement remains stable over time (McCartney, Burchinal, \& Bub, 2006; Singer \& Willett, 2003).

In the current study, we are not concerned with the vocabulary spurt per se. Our goal is to understand whether and to what extent aspects of changes in early language are linked to vocabulary skills at entry to kindergarten. To that end, our first aim is to fit the best model of early vocabulary growth to our longitudinal data of children's cumulative vocabulary production across the 14- to 46-month period, using predictors of individual differences in early growth. In this way, we follow the second body of research mentioned above. However, we then take this work one important step further by using the growth estimates from the early longitudinal model to predict later vocabulary skills at 54 months, just prior to kindergarten entry. This strategy allows us to explore the consequences of variation in early vocabulary growth rates for later vocabulary achievement. According to our theoretical model, children's personal parameters of early vocabulary growth carry important information about their status at school entry. We cannot directly observe these child-specific parameters and must instead use sample estimates of the parameters as predictors. Although this approach has the potential to lead to biased estimates of the association between the parameters of early growth and later outcomes, we introduce a strategy designed to elimi- 
nate bias of this sort (see the Method section). Our approach thus allows us to address an important developmental and methodological question: Does having information about the trajectory that children follow in their vocabulary acquisition (as opposed to having an isolated snapshot of their preschool performance) help predict where children will end up several years later?

We hypothesize that the path children have followed to arrive at a particular level of vocabulary acquisition at a given age may be telling about their future linguistic abilities. Even if there is no true "vocabulary spurt," there clearly is substantial growth in vocabulary size during the 2nd and 3rd years of life (e.g., Fenson et al., 1994). Although the shape of growth often depends on how vocabulary is measured (Pan et al., 2005), on average, early growth tends to be quadratic in nature, with children acquiring more words at a faster rate over time during the 2nd year of life (Ganger \& Brent, 2004; Huttenlocher et al., 1991). Importantly, there is wide variation in children's early vocabulary growth rates (e.g., Fenson et al., 1994). For example, some children start out very slow and then increase rapidly later on, while others start out strong and increase at a relatively constant rate over time. Our hypothesis is that using individual children's growth rates will help us predict later vocabulary size over and above their status at one point in time. This is a plausible hypothesis because the rates of growth likely contain more information about the child's language acquisition potential than their ability at one point in time. If so, we can then explore factors that are responsible for that growth, with an eye toward eventually understanding how to manipulate those factors to improve vocabulary, particularly in children from low socioeconomic backgrounds. We test this hypothesis by first modeling growth in cumulative vocabulary in a sample of 62 children visited on nine occasions (every 4 months) between 14 and 46 months. We examine predictors of growth during this period, using our knowledge of the literature and previous work with the sample. We include three primary background predictor variables gathered at the first (14 months) visit.

The first predictor is SES, measured as parent education and family income. Studies within and across socioeconomic groups have consistently found strong relations between socioeconomic measures and child vocabulary skill. Children from families with higher incomes and/or whose parents are more educated have larger vocabularies, on average, than do their peers from lower income homes with less educated parents (Hart \& Risley, 1992, 1995; Hoff, 2003a, 2003b; Pan et al., 2005). Importantly, some portion of this relation between SES and child vocabulary skill is mediated by the speech that parents offer children on a day-to-day basis (Hoff, 2003b). Thus, SES relates not only to child language outcomes but also to parent input. For example, on average, parents from higher SES backgrounds use more words, more diverse vocabulary, and more complex syntax than do parents from lower SES backgrounds (Hoff, 2003b; HoffGinsberg, 1991; Huttenlocher, Vasilyeva, Waterfall, Vevea, \& Hedges, 2007; Lawrence \& Shipley, 1996; Pan et al., 2005; Rowe, 2008).

The second predictor in the current study is parent input, particularly vocabulary input. To acquire specific vocabulary words children need to be exposed to those words. Of course, word learning is not as simple as mere exposure, yet exposure is a necessary component of the process (Bloom, 2002). The number of different words children hear is thus a reasonable proxy for the vocabulary exposure children experience in their home environments. Note that in measuring vocabulary input, it is impossible to separate the quantity of talk from the diversity of talk, as parents who talk more are likely to use more different vocabulary words (Hoff \& Naigles, 2002). Thus, measuring the number of different vocabulary words a child hears provides information on not only the amount of input the child is getting but also the diversity of the input. Indeed, studies show that children who experience a more diverse vocabulary in their input develop larger vocabularies themselves (Weizman \& Snow, 2001). Moreover, when child vocabulary growth is examined as the outcome measure of interest, the number of different words parents use with their children (parent vocabulary input) is a stronger input predictor than overall talk or syntactic complexity (Huttenlocher, Waterfall, Vasilyeva, Vevea, \& Hedges, 2010; Pan et al., 2005). We thus use parent vocabulary input as a predictor in the current study.

The final predictor is the child's early gesture use (14 months) which has also been found to be a strong predictor of vocabulary skill. For example, we can predict the specific lexical items that will enter a child's vocabulary by looking at the objects to which a child gestured during earlier interactions (Iverson \& Goldin-Meadow, 2005). As another example, "gesture vocabulary" (as measured by the number of items the child gestures to or about) early in development (14-18 months) predicts later vocabulary skill, measured either as child production 
(i.e., word types used during longitudinal parentchild interactions; Sauer, Levine, \& Goldin-Meadow, 2010) or as vocabulary comprehension (the Peabody Picture Vocabulary Test [PPVT]; Rowe, Özçalıskan, \& Goldin-Meadow, 2008; Rowe \& Goldin-Meadow, 2009a, 2009b). Importantly, even though child gesture is obviously a child characteristic, children are not necessarily born high or low gesturers. In fact, SES also relates to early child gesture, a relation that is partially mediated by the gestures parents use in interaction with their children (Rowe \& Goldin-Meadow, 2009b). Thus, children's early gesture use likely encompasses some combination of child ability or motivation to communicate and exposure to a gesture-rich communicative environment.

SES, parent vocabulary input, and early child gesture vocabulary are therefore three important early predictors to consider in our analysis of child vocabulary growth. We also consider the role of child gender, as studies have found an early advantage in language development for girls (Huttenlocher et al., 1991). After presenting our growth models with incorporated predictors, we use the growth estimates from these models to predict children's vocabulary skill at 54 months, just prior to kindergarten entry. Our goal is to determine which aspects of vocabulary growth are related to later vocabulary skill, controlling for SES, parent input, and child gesture.

Finally, we turn to a more practical question. We explore the extent to which child vocabulary data collected early in life predicts vocabulary skill just prior to kindergarten entry. Because the oral language skills children bring with them to kindergarten have a strong relation to their later success in school (e.g., Snow et al., 1998), it is essential to understand how early we can collect measures of child language skill that will reliably predict abilities at kindergarten entry. Thus, we use the child language data collected during the first half of our study (e.g., between 14 and 30 months) to examine how well various measures of early vocabulary skill predict vocabulary prior to kindergarten entry (PPVT scores at 54 months).

Specifically, we ask the following questions:

1. What is the best longitudinal model that describes child vocabulary growth between 14 and 46 months, and how much variation is there in growth rates?

2. What is the role of SES, parent input, and child gesture (our early 14-month predictors) in vocabulary growth?
3. Which aspects of vocabulary development from the longitudinal model best predict children's vocabulary skill at 54 months? In particular, do we improve our ability to predict later vocabulary skill by including a child's velocity and acceleration in early vocabulary acquisition in the model?

4. To what extent can vocabulary data collected very early in life (1-2.5 years) predict children's vocabulary skill at 54 months?

\section{Method}

\section{Participants}

The participants are 62 children and their primary caregivers. These families were recruited via direct mailings to roughly 5,000 families living in targeted zip codes and an advertisement in a free, monthly parent magazine. Interested parents were interviewed about background characteristics and a final sample of 64 families was selected to be representative of the greater Chicago area in terms of ethnicity and income. Annual income levels of the sample varied from less than $\$ 15,000$ to over $\$ 100,000(M=\$ 59,476)$, and children come from more than five different ethnic groups. On average, parents had 15.7 years of education (16 years is equivalent to a college degree) when they entered the study; however, the range was from 10 years (less than high school degree) to 18 years (master's degree or more). Two of the original 64 families dropped out of the study early on; thus the sample considered here contains 62 families. Eight of the families are single-parent families (all mothers). Thirty-two of the children are boys and 30 are girls. All families are raising their children as monolingual English speakers. Table 1 presents the distribution of families by race/ethnicity and income, and makes it clear that income and race/ethnicity are confounded in our sample. For this reason, and because we have very uneven distributions of race/ethnicity, we do not consider race/ethnicity as a variable in our analyses.

\section{Procedure}

Our goal was to get a representative picture of what the typical home environment is like for these children. Thus, parents and children were visited in the home every 4 months between child ages 14 and 46 months, resulting in nine visits covering a 32 -month period. At each home visit, we videotaped parents and children interacting for $90 \mathrm{~min}$ 
Table 1

Demographic Characteristics of the Parents

\begin{tabular}{|c|c|c|c|c|c|}
\hline \multirow[b]{2}{*}{ Family income } & \multirow{2}{*}{$\begin{array}{c}\begin{array}{c}\text { Parents' } \\
\text { ethnicity }\end{array} \\
\text { Hispanic }^{\text {a }}\end{array}$} & \multicolumn{4}{|c|}{ Parents' race } \\
\hline & & Black & White & $\begin{array}{c}\text { Two or } \\
\text { more races }\end{array}$ & Total \\
\hline Less than $\$ 15,000$ & 1 & 3 & 1 & & 5 \\
\hline$\$ 15,000-\$ 34,999$ & 4 & 4 & 4 & 1 & 13 \\
\hline$\$ 35,000-\$ 49,999$ & 1 & 2 & 4 & 1 & 8 \\
\hline$\$ 50,000-\$ 74,999$ & 1 & 1 & 8 & 2 & 12 \\
\hline$\$ 75,000-\$ 99,999$ & 1 & 1 & 7 & 1 & 10 \\
\hline$\$ 100,000$ or more & 1 & 1 & 11 & 1 & 14 \\
\hline Total & 9 & 12 & 35 & 6 & 62 \\
\hline
\end{tabular}

${ }^{\text {a }}$ Those of Hispanic ethnicity are only included once in this table.

"as they normally would." That is, we did not bring any toys with us and instead asked the families to do what they would typically do. We used this research strategy to capture a typical interaction for each family. In seven of the families, the mother and father share the primary caregiving role; as a result, these families sometimes participated in triadic rather than dyadic interactions and parents sometimes alternated interacting with their child. Siblings were present during some of the sessions, but neither their speech nor speech directed to them was included in analysis. The particular activities in which parents and children engaged varied, but a typical session, included time playing with toys, reading a book, and eating a meal or a snack. On some occasions, the session was not quite $90 \mathrm{~min}$ (less than $5 \%$ of the visits); for these visits, we prorated the language data based on the number of minutes missing.

All speech and gestures on the videotapes were transcribed. The unit of transcription was the utterance, defined as any sequence of words and/or gestures preceded and followed by a pause, a change in conversational turn, or a change in intonational pattern. All dictionary words, as well as onomatopoeic sounds (e.g., woof-woof) and evaluative sounds (e.g., uh-oh), were counted as words. Children and parents produced gestures indicating objects, people, or locations in the surrounding context (e.g. point at dog), gestures depicting attributes or actions of concrete or abstract referents via hand or body movements (e.g., flapping arms to describe a flying bird), and gestures having pre-established meanings associated with particular gesture forms (e.g., shaking the head "no"). Other actions or hand movements that involved manipulating objects (e.g., turning the page of a book) or were part of a ritualized game (e.g., itsy-bitsy spider) were not considered gestures. Transcription reliability was established by having a second coder transcribe $20 \%$ of the videotapes; reliability was assessed at the utterance level and was achieved when coders agreed on $95 \%$ of transcription decisions.

The children were again visited in the home prior to kindergarten entry (age 54 months) and were given a receptive vocabulary assessment as described in the next section.

\section{Measures}

Vocabulary skill prior to kindergarten entry. At 54 months, children were administered the PPVTIII (Dunn \& Dunn, 1997) at home. The PPVT is a widely used measure of receptive vocabulary. In this task, children hear a word and are asked to point to the picture (of four options) that matches the word they heard. We were able to obtain PPVT scores for 55 of the 62 children at age 54 months. Thus, the regression analysis predicting PPVT is based on a sample of 55 children, as we chose not to impute data for our outcome measure. There were no differences between the children with PPVT scores $(n=55)$ and the children without PPVT scores $(n=7)$ on SES, parent input, or child gesture measures. The mean standardized score for the sample was $112(S D=18.3)$.

Vocabulary growth during early childhood. Children's vocabulary growth across the nine sessions from 14 to 46 months was measured as their cumulative word types over time. Automated analyses of the transcripts yielded data on the number of different word types (i.e., number of different intelligible word roots) produced by each child at each session. Several decisions were made as to what constituted a word type. Morphologically inflected variants of words (e.g., run, running) were considered a single type. Words produced in imitation of the mother were included in the corpus of child word types, as were words that the parent or child produced while reading. The number of cumulative word types produced at each age served as our measure of vocabulary growth. That is, if a child said a specific word at age 14 months (i.e., cat), the child was given credit for producing cat from that point on, whether the word was produced again or not. This method of measuring vocabulary growth has been used previously in longitudinal analyses (Huttenlocher et al., 1991) and provides less noisy estimates of growth over time. As in most 
longitudinal studies, families occasionally missed a data collection period. The sample of 62 families visited over nine time points resulted in 558 possible visits of which only eight were missing. Thus, less than $2 \%$ of the visits were missed. Because we measured cumulative vocabulary, we imputed values of the "new word types added" for the missing sessions using regression equations from the full sample at the missing age, with age and agesquared as predictors. The imputed value for the missing session was then added to the child's previous cumulative word types to generate the new cumulative word type value for that child. We did not impute values if the missing data point was the final session(s) for that child. In those cases, we left the data as missing and only used the child's data up until that point in the growth models. Overall, only $1.4 \%$ of the vocabulary growth data were imputed.

\section{Early (14-Month) Predictors}

Socioeconomic status. SES was measured as the primary caregiver's education level and family income and was calculated categorically from parents' responses to a questionnaire at or before the 14 month visit. For purposes of analyses, the categories were transformed into a continuous scale of years of education and U.S. dollars. On this scale, parental education ranged from 10 to 18 years, with 12 years equivalent to receiving a high school degree or general education diploma $(M=15.7$, $S D=2.3$ ). The average family income level ranged from less than $\$ 15,000$ per year to over $\$ 100,000$ $(M=\$ 59,476, S D=\$ 31,353)$. In the families where both parents were primary caregivers, we used the education level of the mother; we used this strategy because we were missing father's education level for two of the relevant eight families (and for some others), and because there was a strong positive correlation between mother's and father's education for families where we did have data on both parents $(r=0.62, p<.001)$.

For our full sample, education and income were positively related to one another $(r=0.47, p<.001)$. We consider them here separately at first and then combine them in a composite score to include as predictors in growth models and regression analyses. The composite was generated using principal components analysis (PCA). The first principal component weighted education and income positively and equally. This component accounted for approximately $73 \%$ of the original variance. The mean score of the composite is $0(S D=1.0)$. A fam- ily that scores high on the SES composite thus has a high annual income and a primary caregiver with a high level of education.

Parent input. Parent word types produced at child age 14 months was used as the input measure predicting child language growth because previous work has shown that this measure is a strong input predictor of child vocabulary (Huttenlocher et al., 2010; Pan et al., 2005; Weizman \& Snow, 2001). We calculated parent word types in exactly the same way as child word types, with one exception. Since numerous studies have shown that variation in parent input remains fairly stable over time (Huttenlocher et al., 2007; Rowe, Pan \& Ayoub, 2005), we used parent word types at the first visit as our input measure. Our parent input measure was therefore not cumulative and, in this sense, differed from our child measure. When two parents were present for the interaction, we used the total number of different words produced by both parents, as that was the talk to which the child was exposed. There were six families with two parents present. Input averaged 476 word types for these six families, compared to 367 word types for the remaining 56 families.

Child gesture. The gesture measure of interest at 14 months is gesture types, or the number of different meanings each child conveyed in gesture. We used this particular measure as an early predictor because it is the gesture measure found to be most related to later vocabulary skills (Rowe \& GoldinMeadow, 2009a; Rowe et al., 2008). In calculating gesture types, we followed guidelines in GoldinMeadow and Mylander (1984) and Iverson and Goldin-Meadow (2005). We counted each deictic gesture that indicated a different object as a distinct gesture type. For example, if a child pointed to his dog 10 times during an interaction, those 10 points would count as 1 gesture type ( $\log )$ and 10 gesture tokens. We also counted each conventional or representational gesture associated with a different meaning as a distinct gesture type (e.g., head shake conveying the meaning no; arm flap conveying the meaning flying bird).

Preliminary analyses determined that child gender did not relate to vocabulary growth and therefore was not included in further analyses except when checking for interaction effects. Descriptive statistics for all variables examined here are presented in Table 2.

\section{Methodological Approach}

To address the questions at hand, we present our "theoretical" statistical model, which we then 
Table 2

Descriptive Statistics

\begin{tabular}{|c|c|c|c|c|c|}
\hline Variable & $n$ & $M$ & $S D$ & Min. & Max. \\
\hline \multicolumn{6}{|l|}{ Child age (months) } \\
\hline Visit 1 & 62 & 14.22 & 0.44 & 13.52 & 16.10 \\
\hline Visit 2 & 62 & 18.07 & 0.31 & 17.48 & 19.10 \\
\hline Visit 3 & 62 & 22.13 & 0.34 & 21.48 & 23.29 \\
\hline Visit 4 & 62 & 26.08 & 0.27 & 25.58 & 27.06 \\
\hline Visit 5 & 62 & 30.11 & 0.36 & 29.58 & 31.52 \\
\hline Visit 6 & 62 & 34.12 & 0.31 & 33.52 & 35.35 \\
\hline Visit 7 & 61 & 38.17 & 0.42 & 37.00 & 39.55 \\
\hline Visit 8 & 60 & 42.17 & 0.38 & 41.55 & 43.55 \\
\hline Visit 9 & 59 & 46.27 & 0.44 & 45.35 & 47.39 \\
\hline \multicolumn{6}{|l|}{ Child cumulative word types } \\
\hline Visit 1 & 62 & 13.33 & 13.98 & 0 & 50 \\
\hline Visit 2 & 62 & 47.36 & 38.03 & 1 & 183 \\
\hline Visit 3 & 62 & 127.49 & 85.92 & 4 & 359 \\
\hline Visit 4 & 62 & 238.32 & 130.33 & 6 & 574 \\
\hline Visit 5 & 62 & 355.84 & 154.92 & 18 & 699 \\
\hline Visit 6 & 62 & 469.61 & 171.45 & 44 & 835 \\
\hline Visit 7 & 61 & 588.25 & 179.95 & 127 & 962 \\
\hline Visit 8 & 60 & 690.07 & 193.05 & 235 & 1,121 \\
\hline Visit 9 & 59 & 789.65 & 206.32 & 328 & 1,237 \\
\hline Parent education (years) & 62 & 15.64 & 2.28 & 10.00 & 18.00 \\
\hline Family income (\$) & 62 & 59,476 & 31,353 & 7,500 & 100,000 \\
\hline Parent word types (Visit 1) & 62 & 377.24 & 133.31 & 60 & 708 \\
\hline Child gesture types (Visit 1 ) & 62 & 22.10 & 12.97 & 4 & 58 \\
\hline PPVT 54 months & 55 & 111.89 & 18.27 & 69 & 160 \\
\hline
\end{tabular}

Note PPVT $=$ Peabody Picture Vocabulary Test.

estimate empirically. Our theory is that during early childhood, a child's trajectory of vocabulary growth predicts important aspects of later linguistic functioning. In this longitudinal data set ranging from 14 to 46 months, we use child exact age at each visit as our measure of time and center age at 2.5 years ( 30 months), which is the midpoint of the age range under investigation. We hypothesize that a child's status, velocity, and acceleration in expressive vocabulary at age 2.5 years can help us predict the size of the child's vocabulary 2 years later. The first part of our larger statistical model is a twolevel model that defines child-specific parameters of early vocabulary growth. The second part is a prediction model in which these child-specific growth parameters are explanatory variables and the vocabulary skills prior to kindergarten entry are outcomes.

The two-level model for child-specific growth. The first part of our larger statistical model has two levels: a Level 1 model that accounts for variation in repeated measures within each child; and a Level 2 model that represents variation between children.
At Level 1 (within children), we represent the vocabulary trajectory as a cubic model, so we have, for each child $i$ at time $t$ :

$$
\begin{aligned}
Y_{t i}= & \pi_{0 i}+\pi_{1 i}\left(a_{t i}-2.5\right)+\pi_{2 i}\left(a_{t i}-2.5\right)^{2} \\
& +\pi_{3 i}\left(a_{t i}-2.5\right)^{3}+e_{t i}, \quad e_{t i} \sim N\left(0, \sigma_{t}^{2}\right),
\end{aligned}
$$

where $a_{t i}$ is the age of child $i$ at time $t, \pi_{0 i}$ is child $i^{\prime}$ 's status at age 2.5 years, $\pi_{1 i}$ is child $i^{\prime}$ 's velocity at age 2.5 years, $\pi_{2 i}$ is child $i^{\prime}$ 's acceleration at age 2.5 years, and $\pi_{3 i}$ is child i's cubic change at age 2.5 years. The residual $e_{t i}$ represents that portion of child $i$ 's cumulative vocabulary production at age $t$ that is not predicted by his or her age. We presume a heterogeneous level-q variance, meaning that the within-person variation, $\sigma_{t}^{2}$, varies across time as child age increases.

At Level 2 (between-children), we then hypothesize, based on the previous literature, that an individual child's status, velocity, acceleration, and cubic change may be predicted by our early (14 months) predictors; namely, SES, parent input, and child gesture. So we have Level 2, or betweenperson, models in which there is a separate equation for each Level 1 coefficient, $\pi_{p i}$, where $p=0,1,2,3$ : 


$$
\begin{aligned}
\pi_{p i}= & \beta_{p 0}+\beta_{p 1}\left(\text { SES }_{i}\right)+\beta_{p 2}\left(\text { Input }_{i}\right) \\
& +\beta_{p 3}\left(\text { Gesture }_{i}\right)+r_{p i}, \quad p=0,1,2,3,
\end{aligned}
$$

where $\pi_{p i}$ is the $p$ th growth parameter from the Level 1 model (Equation 1), $\beta_{p 0}, \beta_{p 1}, \beta_{p 2}, \beta_{p 3}$ are linear regression coefficients, and $r_{p i}$ is a random effect. We allow random effects to be correlated within children but not between children.

The prediction model. The second part of our larger statistical model represents the hypothesis that a child's status, velocity, acceleration, and cubic change at age 2.5 years help us predict later vocabulary skill $W_{i}$, controlling for other background characteristics, say $X_{i}$, where $X=\mathrm{SES}$, input, and gesture. We might assume a linear prediction model, that is,

$$
\begin{aligned}
E\left(W_{i} \mid \pi_{0 i}, \pi_{1 i}, \pi_{2 i}, \pi_{2 i}, X_{i}\right)= & \alpha+\gamma_{0} \pi_{0 i}+\gamma_{1} \pi_{1 i}+\gamma_{2} \pi_{2 i} \\
& +\gamma_{3} \pi_{3 i}+\gamma_{4} X_{i}
\end{aligned}
$$

Thus, our goal from Equation 3 is to learn about the $\gamma^{\prime}$ s. In particular, $\gamma_{0}$ tells us how child $i$ 's vocabulary status at age 2.5; that is, $\pi_{0 i}$, contributes to $W_{i}$, controlling for the other aspects of that child's growth curve, as well as background covariates $X_{i}$. Similarly, $\gamma_{1}, \gamma_{2}, \gamma_{3}$ tell us about the unique contribution of the velocity, acceleration, and cubic parameters of child growth net the other predictors in the model.

Equation 3 represents our theoretical belief about the association between early vocabulary growth trajectories and vocabulary prior to kindergarten entry, controlling for child background. Unfortunately, we cannot directly estimate the $\gamma \mathrm{s}$ in Equation 3 because we cannot observe $\pi_{0 i}, \pi_{1 i}, \pi_{2 i}, \pi_{3 i}$. One possible option is to estimate these unknowns, and determine how our outcome (defined by Equation 3) changes as a function of these estimates. For example, we could estimate $\pi_{0 i}, \pi_{1 i}, \pi_{2 i}$, $\pi_{3 i}$ via ordinary least squares regression (OLS), child by child, yielding $\hat{\pi}_{0 i}, \hat{\pi}_{1 i}, \hat{\pi}_{2 i}, \hat{\pi}_{3 i}$. However, simply substituting these values for the true values of $\pi_{0 i}, \pi_{1 i}, \pi_{2 i}, \pi_{3 i}$ would lead to bias, as is well known from the literature on regression with errorprone predictors (cf. Fuller, 1987). However, from the theoretical model in Equation 3, we can derive the conditional mean of the outcome $W_{i}$ given the error-prone estimates $\hat{\pi}_{0 i}, \hat{\pi}_{1 i}, \hat{\pi}_{2 i}, \hat{\pi}_{3 i}$. Thus,

$$
\begin{aligned}
E\left(W_{i} \mid \hat{\pi}_{0 i}, \hat{\pi}_{1 i}, \hat{\pi}_{2 i}, X_{i}\right)= & \alpha+\gamma_{0} E\left(\pi_{0 i} \mid \hat{\pi}_{0 i}, \hat{\pi}_{1 i}, \hat{\pi}_{2 i}, \hat{\pi}_{3 i}, X_{i}\right) \\
& +\gamma_{1} E\left(\pi_{1 i} \mid \hat{\pi}_{0 i}, \hat{\pi}_{1 i}, \hat{\pi}_{2 i}, \hat{\pi}_{3 i}, X_{i}\right) \\
& +\gamma_{2} E\left(\pi_{2 i} \mid \hat{\pi}_{0 i}, \hat{\pi}_{1 i}, \hat{\pi}_{2 i}, \hat{\pi}_{3 i}, X_{i}\right) \\
& +\gamma_{2} E\left(\pi_{3 i} \mid \hat{\pi}_{0 i}, \hat{\pi}_{1 i}, \hat{\pi}_{2 i}, \hat{\pi}_{3 i}, X_{i}\right) \\
& +\gamma_{3} X_{i}
\end{aligned}
$$

Equation 4 shows that if we substitute $E\left(\pi_{p i} \mid \hat{\pi}_{0 i}, \hat{\pi}_{1 i}, \hat{\pi}_{2 i}, \hat{\pi}_{3 i}, X_{i}\right), \quad p=0,1,2,3$ for the unknown $\pi_{0 i}, \pi_{1 i}, \pi_{2 i}, \pi_{3 i}$ in Equation 3, we will obtain unbiased estimates of our $\gamma \mathrm{s}$. These conditional expectations are, in fact, the "Bayes" or "empirical Bayes posterior means" (see Raudenbush \& Bryk, 2002, chap. 6) that we have used in our analysis. Previous work has shown these empirical Bayes estimates to be more precise than estimates from OLS models (Raudenbush \& Bryk, 2002, chap. 6). The key assumption is that the random effects in the Level 2 model (Equation 2) are multivariate normal in distribution. These empirical Bayes estimates can be computed by estimating the two-level model specified in Equations 1 and 2 and then outputting the empirical Bayes (or fully Bayes) coefficients in a child-level file. This is a standard procedure in many software packages for hierarchical linear models. Note that it is essential to include in Equation 2 any covariate $X$ that will also be used in Equation 3.

\section{Results}

The results that follow are presented in four steps. In the first step, we use individual growth modeling (employing HLM; Raudenbush, Bryk, Cheong, \& Congdon 2000) to best model vocabulary growth between 14 and 46 months. We then incorporate the role of early 14-month predictors (SES, input, gesture) in that growth (Equations 1 and 2 above). We then use each child's empirical Bayes estimated growth rates from the vocabulary growth models with early 14-month predictors as predictors of children's kindergarten language skills, using multiple-regression analyses to estimate the parameters of our theoretical model (Equation 3 above). Thus, we are empirically testing a theoretical model based on the assumption that children's trajectories of growth in vocabulary during the toddler period will be good predictors of their later vocabulary skill prior to kindergarten entry. Finally, we turn to the more practical question of the utility of early vocabulary data in predicting later vocabulary skill. Here, we use data from 14 to 30 months and examine relations between vocabulary measures during that early period and PPVT at 54 months.

\section{Modeling Child Vocabulary Growth}

In finding the best model for vocabulary growth, we began with an empirical plot of children's cumulative word types between 14 and 46 months (Figure 1a). As is evident from this plot, children vary both in their rates of vocabulary growth and 
in their estimated vocabulary size at any given age. To obtain the best fitting Level 1, or within-person, model for these data, we fit linear, quadratic, and cubic growth models. All models were fit using heterogeneous sigma squared, meaning that the variation was allowed to vary over time, and age was centered at 2.5 years, the midpoint of the 32-month period. We determined that the cubic model best represented the empirical data because it had the lowest goodness-of-fit statistic ( $-2 \log$ likelihood) and because the plot of the cubic model best mirrored the plot of the empirical data (see Figures 1a,b). A plot of this model is displayed in Figure $1 \mathrm{~b}$. This cubic model shows that, on average, children at age 2.5 years have an estimated cumulative vocabulary of approximately 343 word types, with an increase in cumulative word types at this age at a rate of 362 types per year. Furthermore, the significant quadratic effect indicates that, over time, the yearly rate of increase itself increases, and the significant negative cubic terms suggest that acceleration is not constant and reduces at the later ages. It is not surprising that a cubic model fits the data best, as our videotaped sessions are fixed at $90 \mathrm{~min}$ and thus the potential for adding new words decreases as vocabularies increase and observation time is constrained. The average fitted growth trajectory based on this model is displayed in Figure 1c.

\section{Predictors of Vocabulary Growth}

We next determine the role of the early (14 months) predictors in cumulative vocabulary growth. We begin by examining relations among the predictors themselves. Table 3 presents correlations between parent input (word types) at 14 months, child gesture types at 14 months, family yearly income, and parent education. As Table 3 shows, parent input is significantly positively related to child gesture, to family income, and to parent education. Thus, parents who use more vocabulary with their children, have larger yearly incomes, more years of formal schooling, and have children who gesture to or about more things during the 14 month interaction than parents who use fewer words with their children. In addition to being related to parent input, child gesture is also positively related to parent education (but not to family income), and as noted previously, family income and parent education are positively related to one another.

Table 4 presents a taxonomy of models investigating the relation between early (14 months) predictors and growth in child cumulative vocabulary production. Model 1 in Table 4 is the unconditional cubic growth model. We continue by adding SES as a predictor. Preliminary analyses (data not shown) indicated that when considered on their own, both family income and parent education were significant predictors of intercept and linear change. However, when considered together in the same model, there was no longer an effect of education or income on intercept (and income was a significant predictor of linear change but education was not). Thus, it appears that the predictors are

Table 3

Simple Correlations (Pearson's r) Among Early (14 months) Predictors $(\mathrm{n}=62)$

\begin{tabular}{lllll}
\hline & Input & Gesture & Income & Education \\
\hline Input & 1.0 & & & \\
Gesture & $0.31^{*}$ & 1.0 & & \\
Income & $0.30^{*}$ & 0.06 & 1.0 & \\
Education & $0.36^{* *}$ & $0.30^{*}$ & $0.47^{* * *}$ & 1.0 \\
\hline${ }^{*} p<.05 .{ }^{* *} p<.01 .{ }^{* * *} p<.001$. & &
\end{tabular}

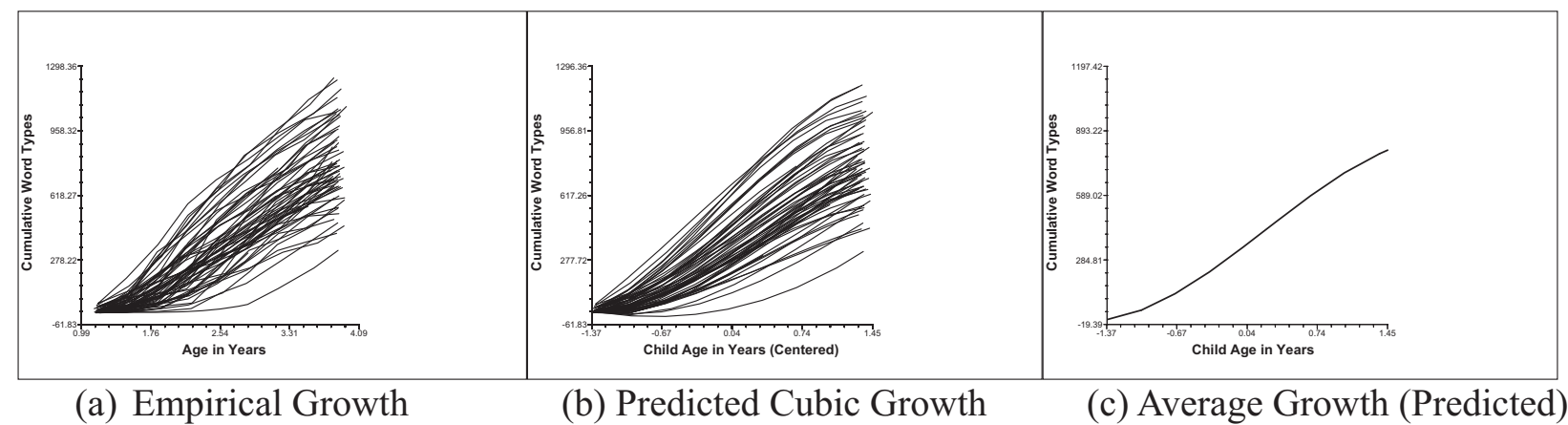

Figure 1. Plots of empirical growth trajectories (a), predicted growth trajectories from cubic model (b), and average vocabulary growth from cubic model (c; $n=62)$. 
too collinear to be considered separately in this analysis; we therefore use the composite created in our PCA as a measure of SES from this point on. Model 2 in Table 4 presents the effect of SES on growth in child cumulative vocabulary production. In this model, the SES composite is a significant predictor of intercept $(p<.05)$ and linear growth $(p<.01)$. That is, children whose parents had higher family incomes and were more educated had greater estimated vocabularies at 2.5 years, and increased in vocabulary at a faster rate, than children from lower SES families. There was no association between SES and quadratic or cubic change. Model 3 in Table 4 shows the effect of parent input, controlling for SES. Here, we see only a marginal effect of input on intercept, and when input is included in the model, the significant effect of SES on intercept disappears. A test of mediation (the Sobel test) showed that the $t$ ratio of $1.51(p=0.12)$ is not sufficient to clearly establish that parental input mediates the associa- tion between SES and child vocabulary. However, the effect is suggestive and should be investigated further with larger samples. Finally, Model 4 in Table 4 presents the effect of early child gesture types on growth in cumulative vocabulary, controlling for SES and input. In this model, controlling for SES and input, child gesture has a significant effect on intercept $(p<.01)$ and a marginal effect on acceleration $(p<.10)$.

The final model containing the effects of SES, input, and gesture (Model 4 in Table 4) is displayed in Figure 2. Here, we examine the role of SES and gesture by plotting four hypothetical trajectories based on higher and lower (75th percentile vs. 25th percentile) SES and gesture levels, holding input constant at its mean. We see that at the earliest ages, the trajectories of vocabulary growth separate, based on whether or not the child is a high or low gesturer. This pattern reflects the marginal effect of gesture on acceleration and the significant effect of gesture on intercept in our model. The two solid

Table 4

Estimates of Fixed Effects, Random Effects, and Goodness of Fit for Cubic Growth Models Using SES, Parent Input, and Child Gesture to Predict Intercept and Change in Children's Cumulative Vocabulary $(\mathrm{n}=62)$

\begin{tabular}{|c|c|c|c|c|c|}
\hline \multirow{2}{*}{ Fixed effects } & $\begin{array}{l}\text { Cubic time } \\
\text { Model1 }\end{array}$ & $\begin{array}{c}\text { Adding SES } \\
\text { Model } 2\end{array}$ & $\begin{array}{l}\text { Adding input } \\
\text { Model } 3\end{array}$ & \multicolumn{2}{|c|}{$\begin{array}{l}\text { Adding gesture } \\
\text { Model } 4\end{array}$} \\
\hline & & & & & \\
\hline Intercept & $342.5^{* * *} \quad(17.8)$ & $342.6^{* * *} \quad(17.1)$ & $342.6^{* * *} \quad(16.6)$ & $342.6^{* * *}$ & $(15.7)$ \\
\hline Linear change & $362.1^{* * *}(12.5)$ & $362.2^{* * *} \quad(11.7)$ & $362.3^{* * *} \quad(11.5)$ & $362.6^{* * *}$ & $(11.2)$ \\
\hline Quadratic change & $28.4^{* * *} \quad(4.6)$ & $28.5^{* * *} \quad(4.6)$ & $28.5^{* * *} \quad(4.5)$ & $28.5^{* * *}$ & (4.5) \\
\hline Cubic change & $-42.8^{* * *} \quad(3.3)$ & $-42.8^{* * *} \quad(3.3)$ & $-42.8^{* * *} \quad(3.3)$ & $-43.1^{* * *}$ & $(3.2)$ \\
\hline SES & & $39.3^{*} \quad(17.2)$ & $26.7 \quad(18.1)$ & 21.5 & $(17.2)$ \\
\hline SES $\times$ Age & & $34.8^{* *} \quad(11.8)$ & $(12.5)$ & $25.8^{*}$ & $(12.3)$ \\
\hline SES $\times$ Age $^{2}$ & & $-1.1 \quad(4.6)$ & $(5.0)$ & 1.0 & $(4.9)$ \\
\hline $\mathrm{SES} \times \mathrm{Age}^{3}$ & & -3.5 & -3.9 & -3.8 & (3.5) \\
\hline Input & & & $0.25^{\dagger} \quad(0.14)$ & 0.15 & $(0.13)$ \\
\hline Input $\times$ Age & & & $(0.09)$ & 0.10 & $(0.10)$ \\
\hline Input $\times \mathrm{Age}^{2}$ & & & -0.03 & -0.01 & $(0.04)$ \\
\hline Input $\times \mathrm{Age}^{3}$ & & & $(0.03)$ & 0.004 & $(0.04)$ \\
\hline Gesture & & & & $3.74^{* *}$ & (1.3) \\
\hline Gesture $\times$ Age & & & & 1.45 & $(0.92)$ \\
\hline Gesture $\times$ Age $^{2}$ & & & & $-0.66^{\dagger}$ & $(0.36)$ \\
\hline Gesture $\times \mathrm{Age}^{3}$ & & & & 0.04 & $(0.26)$ \\
\hline \multicolumn{6}{|l|}{ Random effects } \\
\hline \multicolumn{6}{|l|}{ Level 2} \\
\hline Intercept & $19,421.5^{* * *}(139.4)$ & $17,898.5^{* * *}(133.8)$ & $16,971.5^{* * *}(130.3)$ & $14,995.6^{* * *}$ & (122.5) \\
\hline Linear change & $9,145.5^{* * *} \quad(95.6)$ & $7,938.2^{* * *} \quad(89.1)$ & $7,665.9^{* * *} \quad(87.6)$ & $7,199.3^{* * *}$ & $(84.8)$ \\
\hline Quadratic change & $1,118.7^{* * *}$ & $1,113.3^{* * *} \quad(33.4)$ & $1,105.8^{* * *}$ & $1,054.0^{* * *}$ & $(32.5)$ \\
\hline Cubic change & $425.2^{* * *} \quad(20.6)$ & $414.3^{* * *} \quad(20.4)$ & $410.3^{* * *} \quad(20.3)$ & 374.5 & $(19.4)$ \\
\hline $\begin{array}{l}\text { Goodness of fit: } \\
-2 \text { log likelihood }\end{array}$ & $5,588.1$ & $5,572.9$ & $5,566.7 \quad(26)$ & $5,547.3$ & $(30)$ \\
\hline
\end{tabular}

Note. SES = socioeconomic status.

${ }^{\dagger} p<.10 .{ }^{*} p<.05 .{ }^{* *} p<.01 .{ }^{* * *} p<.001$. 
lines (low gesturers) are lower than the two dashed lines (high gesturers), emphasizing the role of gesture in early vocabulary growth. However, around 2 years of age, the lines start to separate and the effect of SES becomes more apparent. This pattern reflects the significant positive effect of SES on linear growth in our model. From this point on, estimated vocabulary growth is highest for high gesturers in high-SES families, and lowest for low gesturers in low-SES families. Around 3 years of age, the two middle lines become virtually indistinguishable, indicating that a low gesturer in a high-SES family typically has a vocabulary by age 3 that has caught up to the vocabulary of a high gesturer from a lowSES family, controlling for input. These effects are main effects, as we did not allow for a Gesture $\times$ SES interaction in the model. By the final visit at age 3 years 10 months, the difference in estimated vocabulary size for a high-gesture/high-SES child compared to a low-gesture/low-SES child is approximately 200 word types.

\section{Using Growth to Predict Later Language Skills}

To assess the relation between early vocabulary growth and vocabulary skill prior to kindergarten entry, we use the empirical Bayes intercept and growth estimates (see Equation 4) from Model 4 (Table 4) as predictors of children's 54 month PPVT scores. These values are the estimated growth rates derived from the model including SES, input, and gesture as predictors. Not surprisingly, the intercept and growth estimates from the vocabulary growth model are related to one another. For exam-

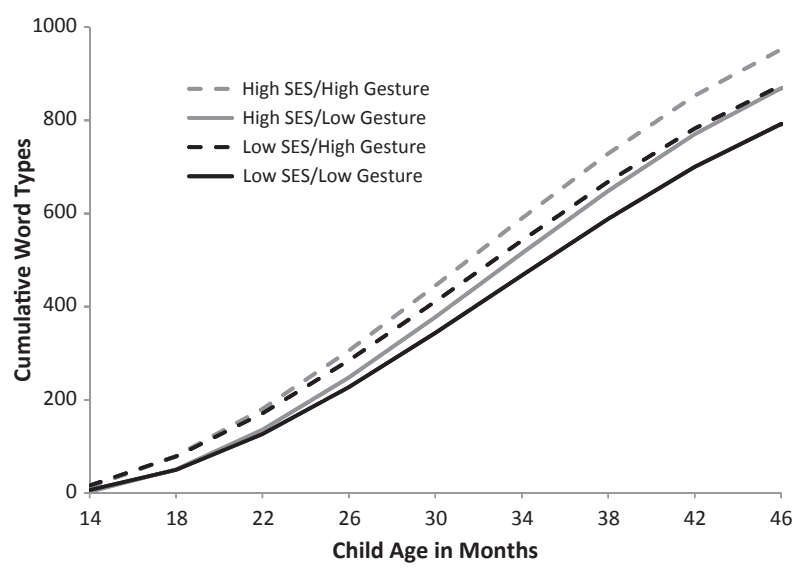

Figure 2. Effect of socioeconomic status (SES) and child gesture on cumulative vocabulary growth, holding parent input constant (at its mean).

Note. High SES and high gesture are plotted at the 75th percentile. Low SES and low gesture are plotted at the 25th percentile. ple, children with higher intercepts or cumulative vocabularies at 2.5 years (based on the full range of data in the model) also show faster linear growth and less acceleration at that time than children with lower cumulative vocabularies at 2.5 years. To determine which aspects of early vocabulary growth (e.g., intercept, linear growth, acceleration) are most related to later vocabulary skill, we fit a series of models comparing growth estimates as predictors. Collinearity was too high to allow for stable estimation in a model containing intercept, linear growth, and quadratic growth (plus controls). As a result, we fit several models containing one or two of the estimates at a time, and then determine the best model based on overall model fit. Note that cubic change was essentially invariant across people; thus, we did not include it as a predictor of 54-month vocabulary.

Model 1 in Table 5 shows that, on their own, the controls explain $43.2 \%$ of the variation in child vocabulary skill at 54 months. In Model 2, when we include the intercept estimates from the growth model, we see that the intercept is significantly and positively related to the outcome, and that the model explains an additional $6.5 \%$ of the variation. Model 3 includes the linear growth estimates from the vocabulary growth models (and not intercept) and shows that linear growth is a significant predictor of later vocabulary, explaining $11.2 \%$ more of the variation over the control only model (Model 1). Thus, a model including linear growth estimates appears to be a better fitting model than one including the intercept estimates.

In Model 4 (Table 5), intercept and linear growth are included together as predictors. The resulting parameter estimates indicate that the predictors are likely too collinear to include together in one model; nevertheless, linear growth remains significant while intercept is not. Model 5 investigates the combined effect of linear growth and quadratic growth. In this model, both linear growth and acceleration are significant predictors of vocabulary skill at 54 months. The addition of acceleration to this model (in comparison to Model 3 with just linear growth) resulted in an $R^{2}$ increase of $3.8 \%$. In Model 6, we include the estimates of intercept and acceleration as predictors. In this model, both estimates are significant and, with controls, explain a combined $56.3 \%$ of the variation in child vocabulary skill. Finally, in Model 7, we present the model with intercept, linear and quadratic parameters as predictors; none of the parameters is a significant predictor because of collinearity. We include this model for comparison purposes only. 
Table 5

A Series of Regression Models Using Vocabulary Growth Estimates From Early Childhood (and Controls) to Predict Pre-K Vocabulary Comprehension $(P P V T ; \mathrm{n}=55)$

\begin{tabular}{|c|c|c|c|c|c|c|c|c|}
\hline & \multicolumn{8}{|c|}{ PPVT (54 months; standardized $\beta$ ) } \\
\hline & Model 1 & Model 2 & Model 3 & Model 4 & Model 5 & Model 6 & Model 7 & Model 8 \\
\hline SES & $0.30^{*}$ & $0.27^{*}$ & 0.22 & 0.17 & 0.14 & 0.18 & 0.15 & 0.15 \\
\hline Input & $0.24^{*}$ & 0.19 & 0.18 & $0.19^{\dagger}$ & 0.18 & 0.16 & 0.18 & $0.24^{*}$ \\
\hline Child gesture & $0.35^{* *}$ & $0.25^{*}$ & $0.28^{* *}$ & $0.35^{* *}$ & $0.31^{* *}$ & $0.23^{*}$ & $0.30^{*}$ & $0.23^{*}$ \\
\hline Intercept & & $0.29^{*}$ & & -0.44 & & $0.73^{* * *}$ & 0.09 & \\
\hline Linear growth & & & $0.37^{* *}$ & $0.77^{* *}$ & $0.56^{* * *}$ & & 0.51 & $0.57^{* * *}$ \\
\hline Quadratic growth & & & & & $0.27^{*}$ & $0.49^{* *}$ & 0.30 & $0.22^{\dagger}$ \\
\hline Linear $\times$ SES & & & & & & & & $-0.33^{* *}$ \\
\hline Quadratic $\times$ SES & & & & & & & & -0.13 \\
\hline$R^{2}$ & 0.432 & 0.497 & 0.544 & 0.565 & 0.582 & 0.563 & 0.582 & 0.651 \\
\hline
\end{tabular}

Note. PPVT $=$ Peabody Picture Vocabulary Test; SES = socioeconomic status.

${ }^{\dagger} p<.10 .{ }^{*} p<.05 .{ }^{* *} p<.01 .{ }^{* * *} p<.001$.

In comparing Models 4, 5, and 6 in Table 5, we conclude that Model 5, which includes linear growth and acceleration, is the best model we can fit to our data to receive unbiased estimates of the role of early vocabulary growth in later vocabulary skill. We cannot use standard hypothesis testing to compare the intercept plus quadratic model (Model 6) with the linear plus quadratic model (Model 5) because they are non-nested models. However, we can see that the latter has a somewhat higher $R^{2}$ statistic (58.2\% for Model 5 compared to $56.3 \%$ for Model 6). Moreover, a useful and entirely appropriate model comparison procedure in this case is the Bayesian information criterion (BIC) (Schwarz, 1978). Applying this procedure, we found that the linear plus quadratic model (Model 5) has a slightly lower BIC (84.08) than does the intercept plus quadratic model (Model 6; BIC $=84.13$ ), consistent with an interpretation that linear plus quadratic give the best account of the data. Furthermore, when we compare Model 5 with nested Model 7 containing intercept, linear, and quadratic growth, we see that we do not explain any more of the variation in PPVT scores by adding the intercept to Model 5 . Thus, we conclude that Model 5, containing the controls, linear and quadratic growth parameters, is the most parsimonious model that we can fit to the data.

Model 5 shows that controlling for important early (14 months) predictors, children's rate and acceleration of vocabulary growth explains a large portion of later vocabulary skill $\left(R^{2}=58.2 \%\right)$. Thus, incorporating early vocabulary growth rates refines our prediction of later vocabulary skill. Specifically, children who have a faster rate of growth during toddlerhood, and who increase in vocabulary growth at a faster rate, have larger receptive vocabularies at 54 months (just before entering kindergarten) than children who have a slower rate of growth and increase in vocabulary growth at a slower rate.

As a final step, we included interaction terms in the model to determine whether the individual growth curve parameters predict PPVT scores differently as a function of control factors, including gender, SES, input, and gesture. In several different models, we added interaction terms to Model 5 in Table 5. For gender, we added the main effect as well because it was not in Model 5. We found no interactions between growth parameters and child gender. A model (data not shown) containing the main effects of SES, input, gesture, linear growth, quadratic growth plus interactions between each growth parameter with each control parameter (linear*SES, quadratic*SES; linear*input, quadratic*input; linear*gesture, quadratic ${ }^{*}$ gesture) resulted in a significant interaction between linear growth and SES. We then fit an additional model removing the nonsignificant interaction effects between growth parameters and input and gesture, and retaining the SES interactions. The results are shown in Model 8 in Table 5. Model comparisons revealed that Model 8 (with the interactions) was a significantly better fitting model than Model 5 (without the interactions) and than the model containing the additional nonsignificant interaction effects (not shown in the table). Thus, Model 8, containing a significant negative interaction between linear growth and SES, is our "final" model.

This interaction indicates that the effect of linear vocabulary growth rates on later PPVT scores is 
stronger for children from lower SES backgrounds. Specifically, controlling for input $(p<.05)$ and gesture $(p<.05)$, the standardized parameter estimate for linear growth in predicting PPVT is 0.892 $(p<.001)$ for a child at the 25th percentile for SES, whereas it is 0.222 (ns) for a child at the 75th percentile for SES. Thus, the rate of vocabulary growth early on in development (30 months) is particularly telling for lower SES children.

\section{To What Extent Can Data Collected Early in Life Predict Later Vocabulary Skill?}

To address our final, more practical question regarding the extent to which early vocabulary production data can be used to predict later vocabulary skill, we take a closer look at the relation between PPVT at 54 months and the data we collected during the first half of our study between 14 and 30 months. We chose to use this period of time because, by 30 months, children already vary widely in the size of their productive vocabularies (Fenson et al., 1994) and because this period is one during which there is much acceleration in vocabulary acquisition (McMurray, 2007). Table 6 presents partial correlations between PPVT at 54 months and children's observed cumulative word types at $14,18,22,26$, and 30 months, as well as the growth estimates (intercept, linear, and quadratic) from a quadratic growth model of vocabulary production across the 14- to 30 -month time period with age centered at 30 months. The partial correlations control for the same variables as in our earlier analysis, namely, SES, parent vocabulary input (at 14 months), and child gesture (at 14 months); these controls were included in the growth model as described in the methods in Equation 3.

As Table 6 shows, controlling for SES, parent input, and early child gesture, child observed cumulative vocabulary does not significantly predict PPVT scores at 54 months until children are 30 months old, at which point the relation is marginal $(p<.10)$. However, both velocity $(r=0.37$, $p<.05)$ and acceleration $(r=0.36, p<.05)$ estimates from the 14-30 month quadratic growth model are related to PPVT scores at 54 months. Thus, having early longitudinal information on expressive vocabulary, including measures of velocity and acceleration, is indeed very useful in predicting later vocabulary skill. In addition, the results suggest that if it is not feasible to collect such detailed data throughout the longitudinal period, collecting data early (at 14 months to gather information on each of the background variables) and then again at
Table 6

Partial Correlations Between PPVT Scores at 54 Months and Early Measures of Vocabulary Controlling for SES, Parent Vocabulary Input (14 months), and Child Gesture (14 months; $\mathrm{n}=55$ )

\begin{tabular}{ll}
\hline & PPVT (54 months) \\
\hline Observed word types (cumulative) & 0.14 \\
14 months & 0.13 \\
18 months & 0.09 \\
22 months & 0.22 \\
26 months & $0.27^{\dagger}$ \\
30 months & \\
Estimates from 14 to 30 month growth model & $0.26^{\dagger}$ \\
(data centered at 30 months) & $0.37^{*}$ \\
Intercept & $0.36^{*}$ \\
Linear growth & \\
Acceleration & \\
\hline
\end{tabular}

Note. Noncumulative observed word types results in the same pattern of correlations as cumulative word types. PPVT $=$ Peabody Picture Vocabulary Test; SES = socioeconomic status. ${ }^{\dagger} p<.10 .{ }^{*} p<.05$.

another later time point (at around 30 months), while not providing measures of growth, might be a fruitful alternative.

\section{Discussion}

The size of the vocabulary that children bring with them when they enter school has been shown to be a good index of their readiness for school and ultimate school success (e.g., Snow et al., 1998). Although research on the course of vocabulary development during the early language learning years has found that children vary a great deal in the rate at which they acquire vocabulary (e.g., Fenson et al., 1994), we have little understanding of the role that these differences in early growth trajectories play in predicting vocabulary skill at school entry. Our study fills this gap by showing that the pace of early vocabulary growth predicts children's vocabulary school readiness skills

We began by fitting the best longitudinal model to our detailed observational data of vocabulary growth between ages 14 and 46 months. We then incorporated background predictors measured at 14 months (e.g., SES, parent input, child gesture) into this growth model and examined the role that those predictors play in children's vocabulary development. Finally, using intercept and growth estimates from our vocabulary growth model, we showed that estimates of children's growth and acceleration in vocabulary during the early childhood period results in the best predictor of vocabu- 
lary skill prior to kindergarten entry and that the relation between growth rates and later vocabulary skill differs depending on the SES of the child. Thus, when predicting children's academic starting point in language skills, we gain the most from looking not only at background factors but also at the early trajectories children are following as their language skills develop during early childhood.

\section{The Role of Background Factors in Child Vocabulary Development: SES, Parent Input, Child Gesture}

The results of our longitudinal growth models support and add to the previous literature on the role that background factors play in child vocabulary development. We find that SES, measured as a composite of parent education and family income, is a significant positive predictor of intercept and linear growth of child vocabulary development. This is not a new finding and replicates previous research by Hart and Risley $(1992,1995)$ and many others (see Hoff, 2006a, 2006b, for a review).

In this study, parent input did not explain the relation between SES and vocabulary growth, but it did reduce the SES effect to a certain degree. However, with SES and input in a growth model together as predictors, SES remains a significant predictor of linear growth and input is a marginal predictor of intercept. Thus, SES relates to children's vocabulary growth even with input controlled (and vice versa, although to a lesser extent). Note that in this study, we used one relatively gross measure of parent input, namely, number of different words directed to the child. It is likely that different aspects of input are more or less influential at different points in development (e.g., Rowe, in press). Thus, our measure of "input" could be an underestimate, particularly since it does not capture differences in quality of input over time. Nonetheless, the positive relation between child vocabulary growth and both SES and parent input suggests that manipulating aspects of the environment may be one way to close the vocabulary gap between children in low- versus high-SES families. For example, parents can be encouraged to increase the diversity of the words they speak to their children, or the gestures they produce along with that speech, which may then have beneficial effects on child vocabulary growth (cf. LeBarton, 2010; Rowe \& Goldin-Meadow, 2009a, 2009b).

Finally, when children's early gesture vocabulary at 14 months is included as an additional predictor, we see a very strong relation between early child gesture and estimated vocabulary skill at 2.5 years (intercept), and a weaker relation between early child gesture and acceleration (quadratic growth). The relation between early gesture and vocabulary growth can be interpreted in several nonmutually exclusive ways. First, it could be that child gesture is merely a good early indicator of underlying linguistic skills and is not playing a role in the process of language learning. Second, it could be that producing gestures for a range of ideas causes children to become good vocabulary learners, perhaps indirectly through the verbal feedback they receive from parents (Goldin-Meadow, Goodrich, Sauer, \& Iverson, 2007), or more directly by enabling them to practice producing meanings with their hands before they can produce them verbally (GoldinMeadow, 2003, 2007). Finally, it is worth mentioning that child gesture at 14 months is related to SES and to parent gesture use at that same time period (Rowe \& Goldin-Meadow, 2009b). Thus, children are not necessarily born high or low gesturers but, as early as 14 months, may have already been socialized to gesture more (or less) during interaction with their parents.

In terms of child gender, the absence of a strong relation between gender and vocabulary growth in our sample is not surprising given the inconsistent findings in the literature. Gender differences have been found either only very early on in language development (e.g., Huttenlocher et al., 1991) or in specific stylistic uses of language, but not in overall vocabulary growth (see Bates, Dale, \& Thal, 1995, for a summary).

To better understand our final growth model, we use Figure 2 to illustrate how the different predictors exert their effects at different points in development. SES and gesture are both significant predictors in our model (controlling for parent input). However, the effect of gesture is most pronounced during the earlier period of vocabulary learning (14-30 months), whereas the effect of SES is most pronounced during the later period (30-46 months). The overall pattern is an interesting one and illustrates the importance of considering both factors: Children who are from higher SES families (whose parents tend to use many different vocabulary words with them) and who themselves produce many gestures conveying different meanings early in development have the greatest estimated vocabularies at 2.5 years and the fastest growth over the early childhood period, children who are from lower SES families and who produce fewer different gestures have the lowest estimated vocabularies at 2.5 years and the slowest growth over the early childhood period, and children with 
mixed profiles (high SES/low gesture and low SES/high gesture) fall somewhere in between and, by the end of the period, are indistinguishable from one another.

\section{Using Growth Trajectories to Predict Vocabulary Size at School Entry}

Our next step was to build an empirical mathematical model to test our theoretical hypotheses about the importance of early vocabulary growth trajectories in later language skills. We obtained estimators of the association between early growth parameters and kindergarten skill using the method of empirical Bayes. These estimators are unbiased under the assumption of the polynomial representation of growth and the assumption that the true growth parameters are multivariate normal in distribution. Both assumptions can be checked (Raudenbush \& Bryk, 2002, chap. 9) and, in our study, were checked using residual plots and alternative specifications. This model-driven approach (Rodgers, 2010) is particularly well suited to vocabulary acquisition, as vocabulary is a construct where the unit of measurement (number of word types) remains stable over the course of development, enabling precise measurement of trajectories. However, the paradigm could, in principle, be used to examine the association between early growth trajectories and later outcomes in other developmental phenomena.

Our findings are intuitively plausible-it is not surprising that vocabulary growth trajectories predict later language skills. After all, vocabulary is one area where we know that there are marked individual differences in rates of growth during early childhood (e.g., Fenson et al., 1994) and these differences are likely to have an impact on the eventual size of a child's vocabulary. Our focus on trajectories, however, highlights the importance of understanding the path of development (Adolph et al., 2008) and the underlying mechanisms of change that create different trajectories of growth (Elman, 2003). The field of language development is approaching consensus on the general shape of vocabulary growth during early childhood (e.g., Ganger \& Brent, 2004) and is making progress on understanding the factors or mechanisms that contribute to individual differences in that growth (see Hoff, 2006a, for a review). However, additional large-scale longitudinal studies that make use of the methods we have introduced here would deepen our understanding of individual differences in language learning and would thus not only move the field forward theoretically but also address the practical concerns involved in optimizing language development (e.g., Hoff, 2006b).

We also found an interesting and important interaction effect showing that the relation between early vocabulary growth rates and later language skill is stronger for children from lower SES families than for children from higher SES families. It is plausible that for children from higher SES homes, the relation between growth and later skill is not as strong because these children have other ways to catch up in the event that they start out behind. Children from lower SES homes may not have these alternate routes, suggesting that it is even more important for children in lower SES homes to get a jump start in their vocabulary learning. Our findings thus speak to the larger issue of the SES achievement gap-it is not only the skills children have when they enter school that matter for later success but also the path they followed in getting to these skills.

Our findings may also have practical significance. Identifying children who are likely to come to school with lagging vocabulary skills well before they arrive at school would be useful so that intervention programs can be made available to them in a timely fashion. In this vein, we examined data from the first half of our observations (from 14 to 30 months) and found that, controlling for SES, parental input, and gesture at the 14-month time point, it was the growth estimates during this period that provided the most useful information about later vocabulary skill, not the data at any one time point. Although it is rarely feasible to gather the kind of detailed longitudinal data that we have collected in our study, it may be possible to collect data at three time points early in development. Collecting background data (SES, parental input, gesture) and data on a child's productive vocabulary at 14 months, combined with child data at two other time points up to 30 months, would allow researchers to construct estimates of linear growth and acceleration and thus better predict vocabulary skill just prior to kindergarten entry. From a theoretical point of view, it is important to note that whether we look at the entire developmental period (from 14 to 46 months) or the truncated period (from 14 to 30 months), including information about the pace of learning vocabulary early in development improves our ability to predict vocabulary skills several years later.

The work presented here does have some limitations, however. First, to get an idea of what each child's typical environment is like, we encouraged 
parents and children to engage in their normal activities at home. This procedure led naturally to a great deal of variability in the activities that the children and parents engaged in, and this variability may have been responsible, in part, for our results. To begin to address this concern, we isolated utterances involved in reading episodes and coded them separately. We found that parents who read more with their children did indeed use more vocabulary with the children than parents who read less. Importantly, however, the pattern of results we report here was the same whether or not the reading utterances were included in the database. Note also that one of our measures, the PPVT, did not involve spontaneous conversation and thus is not tied in any way to the activities that took place during our observations. It is also worth noting that the diversity of activities we saw on our videotapes may be central to the phenomenon we report here and not an artifact of our procedure. The different types of activities the children in our sample routinely experienced at home may have engendered the different types of talk they heard and produced, which, in turn, had an impact on the eventual size of their vocabularies.

A second limitation of the study is the fact that ethnicity/race and SES were confounded in our sample. We therefore were unable to consider how race might (or might not) fit into this picture. Future research with a larger sample is needed to tease these effects apart.

A final limitation of the study is that correlational data do not allow us to talk about causal relations. Studies that experimentally manipulate the variables that we hypothesize play a role in the language learning process are needed for us to take this important step (cf. LeBarton, 2010).

Despite the correlational nature of the work we have presented, the findings do have the potential to influence how we conduct interventions designed to change the course of vocabulary growth. Our findings suggest that we should intervene early, and perhaps in different ways, at different points in development. More specifically, our growth models suggest that early interventions involving child gesture might lead to acceleration in vocabulary growth over time (cf. Rowe \& GoldinMeadow, 2009a, 2009b), assuming of course that child gesture is amenable to intervention (see, e.g., LeBarton, 2010). Interventions that accelerate vocabulary growth early in life have the potential to increase the size of a child's vocabulary at school entry and, in turn, improve school readiness. Our findings thus have particular relevance for populations likely to be behind at the start of kindergarten and thus at risk for reading difficulties and school failure.

\section{References}

Adolph, K. E., Robinson, S. R., Young, J. W., \& GillAlvarez, F. (2008). What is the shape of developmental change? Psychological Review, 115, 527-543.

Bates, E., Dale, P. S., \& Thal, D. (1995). Individual differences and their implications for theories of language development. In P. Fletcher \& B. MacWhinney (Eds.), The handbook of child language (pp. 96-151). Oxford, UK: Basil Blackwell.

Bloom, L. (1973). One word at a time: The use of single word utterances before syntax. The Hague: Mouton.

Bloom, P. (2002). How children learn the meanings of words. Cambridge, MA: MIT Press.

Dickinson, D. K., \& Tabors, P. O. (Eds.). (2001). Beginning literacy with language: Young children learning at home and school. Baltimore: Brookes.

Duncan, G. J., Dowsett, C. J., Claessens, A., Magnuson, K., Huston, A. C., Klebanov, P., et al. (2007). School readiness and later achievement. Developmental Psychology, 43, 1428-1446.

Dunn, L. M., \& Dunn, L. M. (1997). Peabody Picture Vocabulary Test (3rd ed.). Circle Pines, MN: American Guidance Service.

Elman, J. L. (2003). Development: It's about time. Developmental Science, 6, 430-433.

Fenson, L., Dale, P., Reznick, J. S., Bates, E., Thal, D., \& Pethick, S. (1994). Variability in early communicative development. Monographs for the Society for Research in Child Development, 59(5, Serial No. 242).

Fuller, W. A. (1987). Measurement error models. Hoboken, NJ: Wiley.

Ganger, J., \& Brent, M. (2004). Reexamining the vocabulary spurt. Developmental Psychology, 40, 621-632.

Goldfield, B. A., \& Reznick, J. S. (1990). Early lexical acquisition: Rate, content, and the vocabulary spurt. Journal of Child Language, 17, 171-183.

Goldin-Meadow, S. (2003). Hearing gesture: How our hands help us think. Cambridge, MA: Harvard University Press.

Goldin-Meadow, S. (2007). Pointing sets the stage for learning language-and creating language. Child Development, 78, 741-745.

Goldin-Meadow, S., Goodrich, W., Sauer, E., \& Iverson, J. (2007). Young children use their hands to tell their mothers what to say. Developmental Science, 10, 778785.

Goldin-Meadow, S., \& Mylander, C. (1984). The development of morphology without a conventional language model. Papers from the Chicago Linguistic Society, 20, 117-133. [Reprinted in V. Volterra \& C. J. Erting (Eds.). (1990). From gesture to language in hearing and deaf children (pp. 165-177). New York: Springer-Verlag.] 
Gopnick, A., \& Meltzoff, A. (1987). The development of categorization in the second year and its relations to other cognitive and linguistic developments. Child Development, 58, 1523-1531.

Hart, B., \& Risley, T. R. (1992). American parenting of language-learning children: Persisting differences in family-child interactions observed in natural home environments. Developmental Psychology, 28, 1096-1105.

Hart, B., \& Risley, T. (1995). Meaningful differences in the everyday experience of young American children. Baltimore: Brookes.

Hoff, E. (2003a). Causes and consequences of SES-related differences in parent-to-child speech. In M. H. Bornstein \& R. H. Bradley (Eds.), Socioeconomic status, parenting, and child development (pp. 147-160). Mahwah, NJ: Erlbaum.

Hoff, E. (2003b). The specificity of environmental influence: Socioeconomic status affects early vocabulary development via maternal speech. Child Development, $74,1368-1378$.

Hoff, E. (2006a). How social contexts support and shape language development. Developmental Review, 26, 55-88.

Hoff, E. (2006b). The uses of longitudinal data and person-centered analyses in the study of cognitive and language development. Merrill-Palmer Quarterly, 52, 633-644.

Hoff, E., \& Naigles, L. (2002). How children use input to acquire a lexicon. Child Development, 73, 418-433.

Hoff-Ginsberg, E. (1991). Mother-child conversation in different social classes and communicative settings. Child Development, 62, 782-796.

Hoff-Ginsberg, E. (1998). The relation of birth order and socioeconomic status to children's language experience and language development. Applied Psycholinguistics, 19, 603-629.

Huttenlocher, J., Haight, W., Bryk, A., Seltzer, M., \& Lyons, T. (1991). Early vocabulary growth: Relation to language input and gender. Developmental Psychology, 27, 236-248.

Huttenlocher, J., Vasilyeva, M., Waterfall, H., Vevea, J., \& Hedges, L. (2007). The varieties of speech to young children. Developmental Psychology, 43, 1062-1083.

Huttenlocher, J., Waterfall, H., Vasilyeva, M., Vevea, J., \& Hedges, L. (2010). Sources of variability in children's language growth. Cognitive Psychology., 61, 343-365.

Iverson, J. M., \& Goldin-Meadow, S. (2005). Gesture paves the way for language development. Psychological Science, 16, 368-371.

Lawrence, V., \& Shipley, E. F. (1996). Parental speech to middle and working class children from two racial groups in three settings. Applied Psycholinguistics, 17, 233-256.

LeBarton, E. (2010). Gesture's role in facilitating language development (Doctoral dissertation). Retrieved from Dissertations \& Theses (Publication No. AAT 3397260).

McCartney, K., Burchinal, M. R., \& Bub, K. L. (2006). Best practices in quantitative methods for developmentalists. Monographs of the Society for Research in Child Development, 71(3, Serial No. 285).
McMurray, B. (2007). Defusing the childhood vocabulary explosion. Science, 317, 631.

Nelson, K. (1973). Structure and strategy in learning to talk. Monographs of the Society for Research in Child Development, 38(1-2, Serial No. 149).

Pan, B. A., Rowe, M. L., Singer, J. D., \& Snow, C. E. (2005). Maternal correlates of growth in toddler vocabulary production in low-income families. Child Development, 76, 763-782.

Raudenbush, S. W., \& Bryk, A. S. (2002). Hierarchical linear models: Applications and data analysis methods (2nd ed.). Thousand Oaks, CA: Sage.

Raudenbush, R. W., Bryk, A., Cheong, Y. F., \& Congdon, R. (2000). HLM5: Hierarchical linear and nonlinear modeling. Chicago: Scientific Software International.

Reznick, J. S., \& Goldfield, B. A. (1992). Rapid change in lexical development in comprehension and production. Developmental Psychology, 28, 406-413.

Rodgers, J. L. (2010). The epistemology of mathematical and statistical modeling: A quiet methodological revolution. American Psychologist, 65, 1-12.

Rogosa, D. R., Brandt, D., \& Zimowski, M. (1982). A growth curve approach to the measurement of change. Psychological Bulletin, 90, 726-748.

Rowe, M. L. (2008). Child-directed speech: Relation to socioeconomic status, knowledge of child development, and child vocabulary skill. Journal of Child Language, 35, 185-205.

Rowe, M. L. (in press). A longitudinal investigation of the role of quantity and quality of child-directed speech in vocabulary development. Child Development.

Rowe, M. L., \& Goldin-Meadow, S. (2009a). Early gesture selectively predicts later language learning. Developmental Science, 12, 182-187.

Rowe, M. L., \& Goldin-Meadow, S. (2009b). Differences in early gesture explain SES disparities in child vocabulary size at school entry. Science, 323, 951-953.

Rowe, M. L., Levine, S. C., Fisher, J., \& Goldin-Meadow, S. (2009). Does linguistic input play the same role in language learning for children with and without early brain injury? Developmental Psychology, 45, 90-102.

Rowe, M. L., Özçalıskan, S., \& Goldin-Meadow, S. (2008). Learning words by hand: Gesture's role in predicting vocabulary development. First Language, 28, 182-199.

Sauer, E., Levine, S. C., \& Goldin-Meadow, S. (2010). Early gesture predicts language delay in children with pre- and perinatal brain lesions. Child Development, 81, 528-539.

Schwarz, G. E. (1978). Estimating the dimension of a model. Annals of Statistics, 6, 461-464.

Singer, J. D., \& Willett, J. B. (2003). Applied longitudinal data analysis: Modeling change and event occurrence. New York: Oxford University Press.

Snow, C. E. (1972). Mothers' speech to children learning language. Child Development, 43, 549-565.

Snow, C. E. (1994). Beginning from baby talk: Twenty years of research on input and interaction. In C. Gallaway \& B. Richards (Eds.), Input and interaction in 
language acquisition. Cambridge, UK: Cambridge University Press.

Snow, C. E., Burns, S., \& Griffin, P. (1998). Preventing reading difficulties in young children. Washington, DC: National Academy Press.

Stanovich, K. E. (1986). Matthew effects in reading: Some consequences of individual differences in the acquisition of literacy. Reading Research Quarterly, 21, 360-407.

Weizman, Z. O., \& Snow, C. E. (2001). Lexical input as related to children's vocabulary acquisition: Effects of sophisticated exposure and support for meaning. Developmental Psychology, 37, 265-279. 